Please do not remove this page

RMIT

UNIVERSITY

\title{
Written-response interview protocols: an innovative approach to confidential reporting and victim interviewing in sexual assault investigations
}

Heydon, Georgina; Powell, Anastasia

https://researchrepository.rmit.edu.au/esploro/outputs/9921860266701341/filesAndLinks?institution=61RMIT_INST\&index=null

Heydon, G., \& Powell, A. (2017). Written-response interview protocols: an innovative approach to confidential reporting and victim interviewing in sexual assault investigations. Policing and Society: An International Journal of Research and Policy, 28(6), 631-646.

https://doi.org/10.1080/10439463.2016.1187146

Document Version: Submitted Version

Published Version: https://doi.org/10.1080/10439463.2016.1187146

Repository homepage: https://researchrepository.rmit.edu.au

(C) 2016 Informa UK Limited, trading as Taylor and Francis Group

Downloaded On 2023/04/26 21:02:41 +1000 
Thank you for downloading this document from the RMIT Research Repository.

The RMIT Research Repository is an open access database showcasing the research outputs of RMIT University researchers.

RMIT Research Repository: http://researchbank.rmit.edu.au/

\section{Citation:}

Heydon, G and Powell, A 2016, 'Written-response interview protocols: an innovative approach to confidential reporting and victim interviewing in sexual assault investigations', Policing and Society: An International Journal of Research and Policy, vol. 28, no. 6, pp. 631-646.

See this record in the RMIT Research Repository at:

https://researchbank.rmit.edu.au/view/rmit:36980

Version: Submitted Manuscript

Copyright Statement:

(C) 2016 Informa UK Limited, trading as Taylor and Francis Group

\section{Link to Published Version:}

https://dx.doi.org/10.1080/10439463.2016.1187146 


\section{Policing \& Society \\ R) Routledge}

Written Response Interview Protocols: An innovative approach to confidential reporting and victim interviewing in sexual assault investigations.

\begin{tabular}{|r|l|}
\hline Journal: & Policing \& Society \\
\hline Manuscript ID & GPAS-2015-0174.R1 \\
\hline Manuscript Type: & Original Article \\
\hline Keywords: & sexual assault, confidential reporting, written interview, cognitive interview \\
\hline \multicolumn{2}{|c}{} \\
\hline
\end{tabular}


Title: Written Response Interview Protocols: An innovative approach to confidential reporting and victim interviewing in sexual assault investigations

\author{
Total word count (ex bibliography): 8661 words
}

\begin{abstract}
The confidential reporting of sexual assaults can play an important role in support processes for victim-survivors and has the potential to improve the rate of official reporting of sexual assault to police. However the self-reporting forms currently used for this purpose are not developed in line with the research evidence regarding forensic interviewing techniques, and nor have they been trialled and evaluated for their effective use in sexual assault investigations. This situation leads to substantial inconsistencies between the information gathering practices used by police in formal interviews, and the information gathering practices used in confidential, self-reporting contexts. In this article, we engage in a conceptual and critical consideration of current forms used in response to sexual assault. Ultimately, we propose that a Written Response Interview Protocol (WRIP), has potential to improve the completeness and accuracy of evidence, as well as the consistency and experiences of victim-survivors of sexual assault.

(144 words)
\end{abstract}

Keywords: sexual assault; confidential reporting; written interview.

\title{
Introduction
}

There is a well documented 'justice gap' in legal responses to sexual violence (Brown, 2011). Across Western jurisdictions including the United States, Canada, United Kingdom, and Australia sexual violence victimization is prevalent and yet very few cases of rape and sexual assault are reported to police, pursued through the courts, and result in conviction at trial 
(Bohours \& Daly, 2011; Hohl \& Stanko, 2015; Kelly et al 2005; Lonsway, \& Archambault, 2012; McGlynn \& Munro, 2010; Temkin \& Krahé, 2008). The reasons for such case attrition are many and varied; though they include significant under-reporting and case withdrawal by victimsurvivors themselves, as well as decisions made by justice agencies as to which cases will proceed to investigation and prosecution (see Heenan \& Murray, 2006; Leivore, 2005; Murphy et al, 2012). In an attempt to close the justice gap many reforms to sexual offences legislation, as well as to police policy and practice, have been implemented in numerous jurisdictions internationally in recent years. While some of these reforms have resulted in changes to legal definitions (such as to the statutory elements of rape and the meaning of consent), and courtroom processes (such as allowing remote and video-recorded evidence from victim-witnesses), others have been directed at encouraging victims to report sexual offences and improving the responses of police. Given their substantial role in case attrition it is at these two stages of the criminal justice process, initial reporting and police responses, where research suggests some of the largest gains are to be made in responding to sexual violence (Campbell et al., 2014; Daly \& Bouhours, 2014; Heenan \& Murray, 2006; Lievore, 2003; Victorian Law Reform Commission, 2004). Effective reforms at these key stages, it is hoped, can both elicit stronger evidence to support prosecutions as well as promote a more satisfactory experience of justice for victimsurvivors of sexual violence.

This article provides a conceptual exploration of the potential for one such practice-based reform to enhance victim experiences of reporting, as well as the quality of initial evidence gathering, in order to support effective police responses to sexual offences. Given the emerging uptake of anonymous and confidential written reporting options for victim-survivors of sexual assault, we advocate adopting a consistent approach to, and potential expanded use of, these written 
reporting mechanisms incorporating evidence-based research on cognitive interviewing. This approach, which we refer to as a Written-Response Interview Protocol (WRIP) provides a basis for the design of reporting options that is consistent with best-practice interviewing, and maximises the quantity and quality of the information in the report.

In this article, we are concerned with two main types of reporting: i) the forms provided by welfare organisations, law enforcement agencies and other institutions to victim-survivors so that they can make either a confidential or on-record report of a sexual assault, and; (ii) the statement taking process that is used by police officers to record an initial report of sexual assault by the victim-survivor. We consider these current practices for taking victim-survivor reports and the implications of using a WRIP approach in relation to three key concerns. First, negative justice experiences for victim-survivors, who often describe frustration at needing to repeat their account, at the same time as feeling as though their 'whole story' has not been heard. Second, maintaining the integrity of evidence in the context of often inconsistent interviewing approaches and victim-survivors being required to re-tell their account multiple times. Third, missed opportunities for the conversion of confidential, written reports into formal or official reports of sexual assault, which in turn might improve formal justice outcomes (eg. prosecution and conviction rates) for victim-survivors. In this regard, we also consider the legal status of reports made using a WRIP format and their potential admissibility as evidence.

In the following section, we first provide additional background to the prevalence and nature of sexual victimization, as well as victim-survivor experiences of reporting to police agencies, and a brief review of research into their justice needs. Subsequently, we review some current uses of self-reporting approaches, foremost in anonymous and confidential reporting options; as well as adaptive practices reported by some police in a further (separate) study, where written reports 
have been used to work around challenges such as distance and non-recent reports of sexual violence. Thirdly, we review best practice interviewing models and possible advantages and evidence supporting a structured WRIP, the Self-Administered Interview ${ }^{\mathrm{TM}}$, drawing on a case study from Greater Manchester Police, UK. Finally, we consider how current practices might be improved using a WRIP approach in light of the identified concerns relating to victim-survivor justice needs, evidential integrity and conversion rate of reports to criminal cases.

\section{Sexual Victimization, Victim Justice Needs and Police Interviews}

\section{The 'justice gap' for victims of sexual violence}

Sexual violence is a significant and pervasive global problem, which overwhelmingly affects women and girls (World Health Organization, 2013). For example, in the United Kingdom's Crime Survey for England and Wales, one in five women (19.6\%) and 2.7 per cent of men, report having been a victim of a sexual offence since the age of 16 (Ministry of Justice et al., 2013). Similarly in the United States, data from the National Intimate Partner and Sexual Violence Survey reports that one in five women have been raped in their lifetime, with even higher figures for both women and men's experiences of sexual violence more broadly (43.9\% women, and $23.4 \%$ men, see Breiding et al, 2014). Meanwhile, in Australia, figures from the Australian Bureau of Statistics (ABS) report that one in five women have experienced sexual violence since the age of 15, compared to one in 22 men (ABS, 2012). Data such as these illustrate both the prevalence and highly gendered nature of sexual violence victimization.

In addition to the prevalence and nature of sexual violence, international research continues to demonstrate that sexual assault victims are the least likely of all crime victims to report to the police. Indeed, many studies suggest that approximately 80 to 90 per cent of victims do not make a formal complaint (ABS, 2012; Daly \& Bouhours, 2010; Johnson, 2012; Weis, 2010). For 
example, in their systematic review of rape attrition rates across five countries, Daly and Bouhours (2010) found that on average 14\% of victims (as reported to victimization surveys) reported to police. There are many reasons, both personal and systemic, as to why some victims may be reluctant to make a formal report. Personally, many victims may experience fear, humiliation and shame after experiencing sexual violence, preventing their disclosure. Some victims are fearful of reprisal or further violence from the perpetrator - the majority of whom, research suggests, are known to the victim (ABS, 2012; Heenan \& Murray, 2006; James \& Lee, 2014). Moreover sexual assault can leave victims feeling traumatized, both physically and psychologically (Gavey \& Schmidt, 2011; Koss \& Burkhart, 1989; Rozee \& Koss, 2001) - a trauma that may be exacerbated by recounting their experience throughout a long and invasive criminal justice process.

Unfortunately, for those victim-survivors who do report to police agencies, the response they receive and their experience of the criminal justice system varies greatly - regardless of whether their case proceeds to trial. Some victims describe feeling satisfied, even positive, with the way police respond to their report, while others describe feeling as though police investigators were disbelieving, unempathetic, and/or judgemental (Campbell, 2006; Rich, 2014; Spohn et al, 2014). Victims' experiences of their initial contact with police when reporting sexual assault, as well as the early stages of the interview and investigation, are well established as a key factor in whether a victim chooses to proceed or withdraw their complaint (Jordan, 2008; Rich, 2014). Yet, not all police receive training in responding to victim-survivors of sexual assault, nor the specialist interviewing skills for conducting sexual assault investigations (Rich, 2014; Spohn et al, 2014; Spohn \& Tellis, 2014). For example, Rich and Seffrin (2012) found in their survey of 429 police officers in the US, that many were not sufficiently skilled in conducting interviews 
with victims of sexual violence, and there was a correlation between less-developed interviewing skills and high rape myth acceptance.

Daly and Bouhours (2014) further found that of those victims who did report to police, only $15 \%$ proceeded through to conviction. Thus the rewards for reporting with respect to a just outcome are small, given the personal investment and potential negative psychological costs that the process requires from victim-survivors. Indeed, many victim-survivors make rational decisions about whether their experience is worth reporting, in light of such considerations and regardless of the trauma they may have experienced (see Fisher et al, 2010; Weiss, 2011). In short, it is the encouraging of initial reporting, as well as improvements in police responses and practice to reduce the potential negative costs of reporting for victims, where research suggests some of the largest gains are to be made in reducing the 'justice gap' for sexual violence victimization. Hence it is critical to consider the application of a consistent written-response interview protocol to frontline policing as well as to confidential reporting options.

\section{Victims' justice needs}

Much research has sought to identify and understand the needs, interests and indeed meanings of justice from the perspective of victim-survivors themselves (Clark, 2010, 2015; Daly, 2014; 2015). Several recurring justice needs emerge from this extensive body of work. For example, according to Haley Clark $(2010 ; 2015)$ based on her interview study with victim-survivors, 'justice' in response to sexual violence means: acknowledgement and validation of victims' experience; accountability and responsibility of perpetrators; retribution or a 'righting of wrongs', as well as; safety and prevention - an assurance that the harm will not happen again or to others. In a similar vein, Kathleen Daly (2014) describes victims' justice interests as participation, voice, validation, vindication and offender accountability. Additionally, in their 
recent study of victims' experiences of police responses in Victoria (Australia), Martine Powell and Rita Cauchi (2013) found that victim-survivors overwhelmingly highlighted the importance of being treated with dignity and respect throughout the reporting and police investigation process. In in-depth interviews, victim-survivors described six key elements that provided the basis for dignity and respect: being treated as a valued complainant, privacy and anonymity, minimising the number of service providers, timely response, accessibility of services, as well as understanding and keeping appraised of the legal status of the case (Powell \& Cauchi, 2013, p.232).

Indeed, a foremost finding from Powell and Cauchi's (2013) study, was that feeling that their account was valued, that they were worthy of being listened to, and that their experience was worthy of investigation were the most important factors for victim-survivors' experience of the police process. For victim-survivors', a positive experience of reporting to police was 'typically described as one where the victim was allowed to tell their story (at their own pace), and where the officer listened to the story (without judgement)' (Powell and Cauchi, 2013, p. 232-3). Additionally, the experience of feeling listened to and taken seriously was more important to victim-survivors' than whether their case ultimately proceeded to trial (Powell and Cauchi, 2013). The centrality of a positive experience of reporting sexual violence, feeling heard and validated, regardless of the legal outcome of the case, is further highlighted in research both within Australia (Clark, 2010; 2015; Murphy \& Barkworth, 2014; Taylor \& Norma, 2012) and internationally (Elliott et al, 2012; 2104; Knowles, 2013).

Of further relevance to this particular paper, are some of the reasons that victim-survivors of sexual violence give for reporting their experience to police - even when they may not anticipate a just outcome or positive experience for themselves. For example, in Clark's $(2010 ; 2015)$ 
research, victim-survivors described one of their motivations for reporting to police was not to pursue individual justice, but rather out of a desire to provide information that might protect other women from harm. Likewise, in interviews and surveys with victim-survivors, Caroline Taylor found that many women who had reported to police expressed a feeling of obligation and concern for the public good, to provide police with information about a perpetrator who may continue to offend (Taylor \& Norma, 2012). Indeed some women anticipated that their report of the details of a sexual offence and the name of an alleged offender, might be useful to police in building a case against repeat perpetrators - even if the women did not want their own case pursued through the courts. Among their recommendations on the basis of this research, Taylor and Norma (2012, p.34) suggested that there might be some benefit to police taking anonymous and confidential reports of sexual assault, as an alternative 'response to sex crime that meets the needs of survivors in terms of being able to exercise a sense of civic duty'.

\section{Current Uses of Self-Reporting Forms and Written-Response Interview Protocols Anonymous and Confidential Reporting of Sexual Assault}

There are to date no published evaluations of confidential and anonymous reporting, nor studies investigating the extent to which such approaches might: improve the experience of victimsurvivors (and thus meet some of their justice needs); provide useable intelligence for the purposes of law enforcement investigations; and/or encourage victim-survivors to proceed with a formal report to police. However, there is some indication that a proportion of victims' confidential reports, may indeed be converted to official reports. For example, it is estimated that approximately fifteen percent of 'restrictive' (confidential) reports of sexual assault made to the US military, are later converted to official reports by victim-survivors (see Markham, 2015). Moreover, restricted reports appear to be made in addition to unrestricted reports, meaning that 
the informal and confidential reporting scheme is not discouraging victims from reporting formally, but rather encouraging more victims to report at all (US Government, 2009). Given the current low rate of reporting of sexual assault more generally in the community (as discussed at the outset) there is a clear potential for confidential reporting to help close the justice gap for sexual assault victim-survivors.

In the US, a written, anonymous or confidential reporting option appears most common in Higher Education policy and procedure (eg. Karjane et al, 2002; Krivoshey et al 2013), and in military service. For example, in a 2002 report funded by the US Department of Justice, Karjane and colleagues found that 84 per cent of American Institutions of Higher Education offered a confidential reporting option for sexual assault, with just under half offering a completely anonymous reporting option (Karjane et al, 2002, p. ix). More recent research by Krivoshey and colleagues (2013) found that in the US State of Ohio approximately a third $(31 \%)$ of higher education colleges provided a confidential reporting option. Similarly, since 2005 the US Department of Defense has provided both a restricted (confidential) and unrestricted (official investigation) reporting option in response to sexual assault (Friedman, 2007). Despite their varied implementation, confidential and anonymous reporting options are generally supported as an important feature of sexual assault policy and responses, given both the prevalence of sexual assault and significant underreporting of these crimes (Karjane et al, 2002; Krivoshey et al 2013). Indeed, in an Australian Human Rights Commission Review into the Treatment of Women in the Australian Defence Force (2012), Sex Discrimination Commissioner Elizabeth Broderick recommended the introduction of a confidential or restricted reporting option for sexual assault and misconduct in the Australian Defence Force (ADF). The review found that sexual misconduct was significantly under-reported and that providing a confidential option would 
enable an alternative avenue for victim-survivors to access appropriate support and advocacy. Importantly, the review further supported a confidential reporting option, since, as mentioned above, research into similar overseas military policies indicates that fifteen percent victims who initially make a confidential report go on to make a formal report, after having access to support and advice. That confidential reports might provide a mechanism through which victim-survivors might build resilience, access support, and ultimately decide to make a formal report, is further supported in the broader literature (eg. Heffron et al, 2014).

Confidential, and anonymous, paper-based reporting options have also been introduced in some state police agencies in recent years. For example, in Australia the Queensland Police Service has operated an Alternative Reporting Option (ARO) for sexual assault since 2006, formerly under the title Project USA - Unreported Sexual Assault (J. Keith, Behavioural Specialist Unit, Queensland Police Service, Personal Communication, May, 2015). In a government factsheet ARO is described as providing an opportunity for healing for victim-survivors, as well as assisting police with information that might assist investigations into other reported offences (Royal Brisbane and Women's Hospital, 2013). New South Wales Police launched SARO (Sexual Assault Reporting Option) in January 2012 as an alternative for those victim-survivors who did not want to pursue a formal report and investigation. Victim-survivors can now also report using either a paper-based or online form, on which they can choose to remain completely anonymous (and thus provide the information solely for police intelligence purposes), or to provide their information and permission to be contacted by police in a subsequent investigation. At the time of writing, Queensland and New South Wales are the only Australian jurisdictions to offer these self-reporting approaches to either anonymous or confidential reporting of sexual assault. 
Anonymous reporting of sexual assault is also increasingly available in a less formal context via mobile phone applications (or 'apps') and through websites or online forms. For example, a US smartphone app Assault, Services, Knowledge: ASK $D C^{l}$ includes a panic button to call police, the ability to share a GPS location with selected contacts and send alerts to friends, as well as information and referral to local services for victims of sexual violence in Washington DC (see also Rich, 2013). The data from anonymous reports are compiled and analysed to identify localized trends and sexual assault 'hotspots' that may assist police in directing their patrol resources or indeed in investigations. Meanwhile, in Australia, the South Eastern Centre Against Sexual Assault (or SECASA) in Melbourne received a government grant of $\$ 20,000$ to develop a Sexual Assault Anonymous Reporting app-SARA for short-launched in March 2013 (Donelly, 2013). The app allows victims of sexual violence, whether it is a current or recent sexual assault, harassment or past assault, to enter details of the violence into the app such as the offenders' characteristics, when and where it occurred, the type of assault and even an image or short video taken of the scene.

In a further example launched in the US in August 2015, Project Callisto ${ }^{2}$ has been developed as an online confidential reporting tool for college sexual assault survivors (Sexual Health Innovations, 2015). According to the tool's developers:

Callisto allows sexual assault survivors to complete an incident report online, receive a clear explanation of their reporting options, and then either directly submit the report to their chosen authority or save it as a time-stamped record. Survivors saving a record can

\footnotetext{
${ }^{1}$ Available at: http://www.assaultservicesknowledge.org/

${ }^{2}$ Available at: www.projectcallisto.org
} 
$\log$ back in at any time to officially report their assault or can choose to have their report automatically submitted to the authorities if someone else reports the same assailant. ${ }^{3}$

The potential benefits of anonymous reporting apps such as SARA or ASK DC extend beyond the offending patterns data that may be made available to assist police. Sexual assault services such as SECASA hope that providing victims with a positive experience of reporting sexual assault anonymously online, of being heard and having their experience counted, may assist victims in their recovery and even encourage them to report an incident formally to police in the future (Jalote, 2013, see also Powell, A, 2015).

If there is indeed a likelihood that some victim-survivors may wish to convert an initially confidential and informal report, into an official report, then the quality, accuracy, and detail recorded in the initial confidential report could be crucial to the success of a subsequent investigation and court case proceeding.

\section{Adaptive responses of police taking initial reports of sexual assault}

It has been well established that the information obtained in victim-survivors' initial statement to police is critical to prosecution, particularly as cases often centre on the accounts provided by both the perpetrator and the victim and rarely with third-party or corroborating evidence (see McMillan \& Thomas, 2009). As the key 'witness' to the alleged crime, it is crucial that victimsurvivors are able to provide an accurate and complete account of what happened. However, as the research literature in the US, UK and Australia in particular demonstrate, some police continue to engage in 'aggressive questioning' of victim-survivors of sexual assault (Campbell, 2005; Jordan, 2004; Maier, 2008; McMillan \& Thomas, 2009; Martin, 2005). Such questioning

\footnotetext{
${ }^{3}$ Available at: https://www. sexualhealthinnovations.org/initiatives/
} 
may be marked by frequent interruptions to the victim-survivor's narrative, with probing questions asked for clarity or additional detail, though victims also report such questioning can feel as though investigators doubt the truth of the account (see McMillan \& Thomas, 2009). Furthermore, rather than a complete record and transcript of the information spoken by a victim (and thus in their own words), victim-survivor statements are routinely typed by an investigator during the interview, and therefore are inevitably an interpreted statement written by the investigator. In a separate study regarding the role of technology in sexual violence (see Powell \& Henry, in press), a specialist sexual offences investigator described it this way:

If I write someone's statement, if you lined up twenty of them, there's probably a consistent format and what you then have to be careful of is - I suppose - a colouring or influencing of the content. If someone's reporting something and it's in their words and it's quite clear... I think that probably it has a lot of benefit.

Indeed there are a variety of examples where police may use written accounts, such as via email, as a tool for preparing an initial statement from the victim-survivor. For instance, where rurality and the time-lag in scheduling an interview with a specialist sexual offence investigator prevents a timely interview when a report is made, or where a victim-survivor contacts police but is reluctant to make a formal report. A further example is in historical sexual assault cases where the same sexual offences investigator provided this description of using email to document victim-survivor accounts:

I've used, I suppose as a bit of a tool, I've used this lots where someone will come in and report a historical offence and it might be something that's happened throughout their life. For example, it might be, say, a 35 year old person reporting something that 
happened to them between the ages of 15 or 25 or something like that. And rather than sit down and have a great big long conversation with that person - and this is just loosely as an example - I get some brief details from them. And then I give them my email address and send them away and ask them to type it out. And in one case I had...when this person came back, he came back with a memory stick with a Word document on it that was 19 pages long. And that became his statement. And the benefit of that is it is in his words. And it is untainted by anybody else. It is all his words.

There is arguably potential, in light of such adaptive practices by some police, to provide a consistent and evidence-based WRIP approach that may be used in such instances.

\section{Improving police interviewing in sexual assault investigations}

The importance of obtaining a detailed account from the witness in their own words has long been the cornerstone of best-practice police interviewing. In the Victoria Police, this is currently represented by the Whole Story approach to interviewing witnesses and victim-survivors of sexual assault (Tidmarsh et al 2013), which is closely aligned with earlier models of interviewing developed in the United Kingdom that prioritise the interviewee's free narrative description of events.

Since the introduction of tape recorders into police interview rooms in the UK in 1984 (Police and Criminal Evidence Act, UK 1984), the police service of England and Wales has been engaged in a long term program of research and training aimed at improving the quality and reliability of interview evidence (ACPO 2009, Griffiths and Milne 2006, Milne and Bull 1999). Although the changes to interviewing under PACE were primarily directed towards improving interviews with suspects (Baldwin 1993), in fact the first and most influential interviewing protocol that was developed was one that focused on the interviewing of witnesses (Clarke and 
Milne 2001). In particular the training introduced across England and Wales from 1992 was based on the finding that a narrative interviewing approach could maximise the witness's recall and reporting of events. The new model drew on research from the USA that demonstrated that certain questioning and cognitive priming techniques could improve both the amount and accuracy of detail provided by interviewees (Geiselman, Fisher, McKinnon and Holland 1985). These specific techniques, collectively known as the Cognitive Interview, were incorporated into a training model for recruits in England and Wales, named using a mnemonic 'PEACE', which stood for the five stages of interviewing under the protocol: Planning and Preparation; Engage and Explain; Account; Closure; Evaluation. A crucial difference between the PEACE model and traditional approaches to interviewing witnesses was the elicitation of a free narrative from the witness at the start of the interview, following very carefully designed cognitive priming strategies. Previously, police officers would take a statement from a witness in what was essentially a form-filling exercise. There had been no research to support the use of particular questions, and the influence of the wording, or the order of, police questions on the witness statement was not considered relevant or important. Indeed, witness 'statement-taking' was not generally considered a priority task in an investigation compared with the interviewing of suspects (Baldwin 1993).

Extensive research over the last four decades has supported the use of open-ended requests designed to elicit free narrative responses from interviewees in police interviews (Powell, Fisher and Wright, 2005). The specific techniques that increase the quantity and quality of interviewees' recall of events - the cognitive interviewing techniques originally devised by Geiselman and Fisher (see above) - continue to dominate the field of investigative interviewing in the UK and most of Australia. Some agencies in Canada (Snook, Eastwood, Stinson, 
Tedeschini, and House 2010) are also beginning to adopt these methods, although the more coercive Reid Method ${ }^{\mathrm{TM}}$ of interviewing continues to prevail in North American law enforcement agencies.

The cognitive interviewing approach is clearly supported by studies investigating victim-survivor experiences of justice in reporting sexual assault to police (Powell and Cauchi 2013; Westera \& Kebbell 2014). The focus on eliciting a free narrative means that victim-survivors have the opportunity to tell their story in their own words, which is more likely to provide a sense of being listened to and valued by police than a form-filling exercise dominated by a police agenda. The free narrative-based cognitive interviewing model is therefore not just a tool for eliciting more reliable and detailed evidence, but it is also more likely to provide a positive experience for the victim-survivor in sexual assault complaints. And, as we will demonstrate below, the free narrative approach, and the specific strategies and mnemonics that are used in cognitive interviewing, are just as relevant to maximising the quality and reliability of written reports as they are to improving face-to-face interviews.

In the following section, we turn to consider the current uses of self-reporting forms and WrittenResponse Interview Protocols (WRIPs) in response to sexual assault. In particular, we discuss a

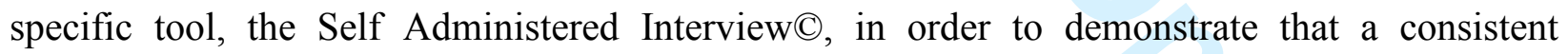
approach, based on best practice investigative interviewing, can be used to inform and improve current ad-hoc and informal self-reporting approaches.

\section{The Self-Administered Interview (C)}

Research in the investigative interviewing field has now turned to consider a wider variety of interviewing scenarios than the prototypical cases involving a small number of witnesses who can be interviewed almost immediately by police. Cognitive interviewing has always been 
concerned with the fragility of memory and the tendency of the witnesses' memories to deteriorate and become contaminated with conflicting information from other sources as time passes. Cases where the interviewing of witnesses is delayed are of particular concern because, while a witness might retain a general set of memories in relation to the events, potentially crucial evidentiary details are more susceptible to deterioration over time.

There are many reasons why there might be a delay between the alleged crime and the police interview with the witness, such as reticence on the part of the witness in coming forward, injury sustained by the witness that prevents them speaking, difficulty in identifying witnesses, or a very high volume of witnesses that need to be interviewed. In an attempt to address this problem, some recent research has focused on developing tools that might be used to alleviate the deterioration and contamination of memory caused by operational delays when police must interview many witnesses to events such as traffic accidents or terrorist attacks. The resulting tool is called the Self-Administered Interview $\mathbb{C}$ (Gabbert, Hope and Fisher 2009) and has been extensively tested in both laboratory and field conditions (Hope, Gabbert and Fisher 2011). The SAIC is a paper document that can be handed out by police to bystanders at the scene of a crime. It provides a structured set of instructions to the users that takes them through the same memory enhancing steps of a cognitive interview, but in written form. In testing, the SAIC has been found to elicit as much if not more detail as a comparable face-to-face interview, and with equivalent levels of accuracy. Trials of the SAIC by Greater Manchester Police have been successful and the tool has been implemented in several police forces since (Hope, Gabbert, Heaton-Armstrong, \& Wolchover 2013).

While the SAIC forms were not originally designed for use in sexual assault investigations, evidence from Greater Manchester Police and case studies presented by the authors of the tool 
indicate that the forms can play an important role in sexual assault cases, for a number of reasons (Hope et al 2013: 41). Former specialist investigative interview advisor to Greater Manchester Police, Mick Confrey (Personal Communication, May, 2015) reports that in some sexual assault cases, the $\mathrm{SAI} C$ is provided by investigators to victim-survivors while waiting for the medical examination to take place. As the victim-survivor cannot be interviewed until after they have been medically examined, provision of a written-report interview protocol during that waiting period can serve two purposes - it can provide the victim-survivor with a sense that the investigation is progressing, and it can prevent further deterioration of the victim-survivor's memories (see also Hope et al 2013, and below).

In a case study reported in Hope et al (2013: 41) the SAIC was used to interview the victim of a violent assault who wanted to make a formal complaint but whose injuries included a broken jaw that prevented her from responding verbally in an interview. While the victim awaited surgery, police were able to provide her with an SAIC through which she was able to identify the assailant who was being held in custody. In this case, the use of a WRIP to circumvent the delay to interviewing caused by the victim's inability to speak properly meant that the suspect could be positively identified and interviewed expeditiously as required by law, and the victim's memory of the event was preserved in a detailed written account before it had a chance to deteriorate any further.

Extensive laboratory and field testing of the SAIC has demonstrated that an appropriately designed WRIP can produce a witness statement that is equal in detail and reliability to a standard interview statement. The examples of the SAIC given above, though they are isolated cases, document some adaptive practices of police in responding to sexual assault incidents by using written-response interview protocols. They indicate that a WRIP can assist the 
investigation when a face-to-face interview is not immediately possible, and is likely to be significantly delayed. Together these two factors support future research to test and evaluate a WRIP in anonymous reporting of sexual assault, especially given the current ad hoc and untested use of written reporting tools by support service providers and police (see further below).

\section{Implications for current practices}

While the implementation of a WRIP tool would require further research, testing and evaluation, this paper draws together the relevant literature and best practice models in order to identify the key features of a reporting tool for sexual assault that can address the three concerns raised above: justice experience for victim survivors; protecting the integrity of the evidence; and improved conversion of reports to cases, where evidence provided in a WRIP is admissible in court. In this section, each of these three concerns is discussed in relation to current practices, drawing on examples of reporting schemes and sexual assault support agency initiatives already in place, and identifying aspects of those schemes which might benefit from the shift towards a WRIP approach.

\section{Consistent and enhanced justice experience for victim-survivors.}

In the case of a sexual assault, there is a foremost potential advantage to using a WRIP which may improve the victim-survivor's experience of reporting the assault. As discussed previously, any approach to interviewing based on the prioritisation of the witness's free narrative is likely to provide the opportunity to victim-survivors for a more positive experience of reporting sexual assault to police. An appropriately designed WRIP offers women and men in this situation the chance to write their story in their own time, with prompts and guidelines carefully designed to maximise recall and focus the writer on key aspects of the events in question. It may also 
provide a 'first response' which demonstrates that the report is being taken seriously, adopting a 'write down everything' approach, prior to a formal interview.

As discussed throughout this article there are many different examples of contexts in which a consistent and evidence-based WRIP approach may be an effective tool. This includes: in timelag situations such as while waiting for forensic nurse examination, waiting for a specialist sexual offences investigator to conduct in-person interview (especially in regional/rural areas), responding to historical sexual assault, providing quality and consistency in confidential reports to increase their utility for conversion to an official report, and in cases where a victim makes an initial report to police, but is reluctant to proceed with a formal report at that time.

A further instance where a WRIP tool may be effective is in providing a form translated into community languages allowing victim-survivors, for whom English is not their first language, to document their account as soon as possible in their own words; possibly while waiting for an appropriate interpreter to be available for a subsequent interview with a police investigator. In fact, adopting a WRIP for use in such situations might offer significant advantages due to the improved accuracy of translating written language compared with interpreting spoken language. In particular, Heydon and Lai (2013) find that the lengthy narratives produced by witnesses in cognitive interviews create a specific difficulty for interpreters who struggle to maintain accuracy when rendering longer turns at talk into the target language. This problem can be substantially mitigated by the use of a WRIP to capture the witness's account in writing with minimal loss of detail in translation. This also results in a complete record of both the original and translated account that can be examined, checked with the witness and corrected prior to an interpreter-mediated police interview. 


\section{Protecting the integrity of the evidence}

Research into interviewing and the priming effect of different question types indicates that using a series of closed questions to elicit specific responses at the start of an interview has a 'training' effect on the interviewee, and builds an expectation that all responses should be similarly short and specific. Investigative interviewing models such as the NICHD protocol for use with children who are victims or witnesses of violent or sexual assaults, emphasise that vulnerable witnesses need to be trained to provide detailed narratives, and this includes avoiding a series of 'form-filling' questions to start the interview (Lamb, Sternberg, and Esplin, 1994: 268). Instead, children are given practice exercises, like describing their whole morning from when they woke up to when they left home to come to the interview, and they are guided towards more and more detailed descriptions, until they are clearly exhibiting an understanding of the level of detail that is required in their answers to 'tell me everything' questions. Even with adult witnesses, the cognitive interviewing principles established by Fisher and Geiselman include a 'report everything' instruction, which refers to the need to explain to witness explicitly that a detailed narrative response is required. A typical example of this 'report everything' instruction is:

Tell me everything you can remember, even the little things that you think are not important, and even partial details. Remember, I was not there; you were there so just tell me everything you can remember in your own time. (ACPO 2009)

In stark contrast to these well-established interviewing practices, the questions used to elicit information from victim-survivors in the current self-reporting forms are predominantly closed questions that require specific responses. In the example provided above of the smart phone and web application, SARA, the form includes several free-text fields relating to the description of the offender and the location, however most are prefaced by closed questions, or simply 
headings, for instance 'Offender height'. Towards the end of the SARA form, there is an opportunity for the user to provide a narrative response to the question: 'Tell us what happened' under a heading 'About the incident'. This is the main narrative report where we would expect the most valuable information to be provided, and yet its placement at the end of the form does not maximise the likelihood that the user will provide a detailed narrative.

Other reporting mechanisms used by agencies and even by the police themselves follow the same format, prioritising tickboxes and short answer questions by placing them at the top of the form, and leaving a request for a narrative account of the incident until the end of the form. The NSW Police Sexual Assault Reporting Options (SARO) Questionnaire is formatted thus and respondents are offered three pages of tickboxes and short answer questions before a space is provided for a "Summary of Incident". The Queensland Police Sexual Crime Survey form follows the same format with seven pages of tickboxes and short form questions before providing space for a narrative, and the Queensland Bravehearts Inc Sexual Assault Disclosure form, while much shorter, does not request a narrative about the incident at all, but only a space for 'Any other information you would like to add.' These four reporting mechanisms are, to date, the only available sexual assault written reporting tools in Australia.

University colleges in the USA are prominent amongst organisations seeking to address sexual assaults amongst their population, and several provide forms for anonymous reporting of incidents. A form provided by the MIT Police Department in Michigan, USA does not include any space for a narrative account, and only provides a series of tickboxes. The same format is used in a form from Chapel Hill Police Department North Carolina. A form provided by the University of Pittsburgh requests an account of the narrative after two pages of tickboxes and short form questions. Not one of the forms that we examined included any cognitive 
interviewing strategies that might assist respondents to recall details. In fact, every form presented its requests for information in a format that utterly contradicts the findings of the last four decades of empirical research into witness interviewing questioning protocols. While our sample is undoubtedly not exhaustive, it represented every sexual assault reporting form available publicly online in the USA at the time of writing. It was notable that most of the forms appeared to be based on the same template, or were near copies of each other.

A WRIP that could be used for anonymous reporting of sexual assault needs to incorporate instructions to users that are consistent with the Cognitive Interview techniques. Therefore, rather than a form that initially gathers specific details and then provides an opportunity for a narrative response, a WRIP for anonymous reporting must commence with an 'Engage and Explain' phase that includes the cognitive interview 'report everything' instruction. While anonymous reporting is necessarily de-personalised, it does not have to be de-humanised, and the literature on interviewing is clear that some attempt to engage with the interviewee will help to maintain good cognitive function. Thus, the initial instructions to users must be carefully constructed so as to engage them in the reporting process sensitively, and at the same time provide the necessary guidance about the recall and reporting process.

Evidence from tests of the SAIC have demonstrated that in circumstances where an immediate witness interview is not possible, the SAIC ensures that a full account is elicited from the witness, rather than a partial account (Hope et al 2013: 41). This is crucial to the investigative importance of the account, because it facilitates immediate action by police investigators based on the most accurate information available. In addition, the use of a research-based tool like the SAIC also provides an assurance that the victim-survivor's account has not been contaminated 
by leading or inappropriate questioning by inexperienced police officers or other personnel involved in the case.

\section{Conversion to formal reports and admissibility as evidence}

As discussed earlier a strong motivation for agencies to adopt a self-reporting option is the potential conversion of confidential reports of sexual assault to formal police reports. Research conducted by the US military found a conversion rate of around fifteen percent (Markham 2015) and this represents a significant opportunity for improvements to prosecution and conviction rates. However, a key consideration for successful prosecution of sexual assaults is the strength of the victim-survivor's testimony, given the usual paucity of any other evidence in the case. A well-documented and detailed initial report, even one made confidentially, has the potential to substantially reinforce the quality and credibility of a victim-survivor's testimony in court, and is therefore of considerable interest to police prosecutors.

In the UK, the legal status of the reports provided using the SAITM form have been examined in detail in research by Hope et al (2013). This series of paper finds that although the forms are not signed by witnesses in accordance with the legal requirements for witness statements used as evidence in English and Welsh courts, there are circumstances where a completed form could be admitted in place of a 'live' witness examination at the discretion of the judge. Where the witness is appearing live in court to give evidence based on their interview, a written statement made by the witness prior to the formal interview can be used to establish the truth and accuracy of the facts in the interview, in accordance with s.120 of the Criminal Justice Act (UK) 2003.

In Australia, the Court might admit a completed form in the presence or the absence of the witness but the circumstances in which this could occur are complex and it is beyond the scope of this paper to present the legal arguments around admissibility. Consideration of the legal 
status of WRIPs, such as that presented by Hope et al (2013) in relation to the SAITM, will require a careful investigation of a number of factors, including hearsay rules and establishing the reliability and circumstances of the report where it is used to support the credibility of the witness. Pending the outcome of this legal research, the value of a WRIP for investigative purposes or for anonymous reporting of sexual assault remains undiminished, and the admissibility of the reports in English and Welsh courts does provide some basis for optimism that WRIPs might be found have an evidential status in Australian jurisdictions.

\section{Challenges and limitations}

While the discussion here has focused on the potential advantages of a consistent and evidencebased WRIP approach, there are nonetheless some important challenges and limitations. Clearly, the capacity for victim-survivors to write down an account of their experience is dependant on their literacy although, as discussed above, in a linguistically and culturally diverse society there is also potential advantage in providing a translated WRIP form in community languages and allowing victims/witnesses to provide an account in their first language.

A further challenge is the capacity of victim-survivors to tell their 'whole story' where words and normative taboos often fail to allow for the expression of trauma (see Henry, 2010; Powell, A, 2015). For example, in an interview study by McMillan and Thomas (2009, p. 272), victims described words failing them in police interviews, as one woman explains:

I think it would always be hard, impossible maybe. These are things we don't talk about, language you don’t use, especially with a stranger - talking about my vagina, my body I could barely find words for what they wanted, needed, me to tell them about.

There is no guarantee that victim-survivors would be better able to provide the detailed description of sexual assault necessary for a police investigation in writing than in a face-to-face 
interaction with police. The social taboos that make speaking in sexually explicit terms about the rape inherently embarrassing might be reduced when writing, as compared to speaking 'out loud', to an investigator. Yet, describing a sexual assault whether written or spoken will nonetheless remain a difficult process. While some research suggests that there may be little to no difference in accuracy between written and spoken witness accounts (see e.g. Sauerland et al., 2014), a WRIP approach might provide the opportunity for victim-survivors to provide an initial account in a less confronting environment.

It is worth bearing in mind that we are not advocating that the WRIP approach serve as a replacement for an investigative, face-to-face interview by police. Rather, it may serve as a 'first response' tool that may go some way towards addressing practical limitations and delays in securing a police interview, as well as responding to the justice needs of victim-survivors feeling that their report is being taken seriously. There are also clear potential advantages to a WRIP approach, which is designed to preserve the details of a victim's narrative using tested techniques, to elicit an account before the inevitable erosion of the victim-survivor's memories over time. Finally, while there is as yet little empirical and evaluative data available, there is potential for the availability of a confidential WRIP approach to increase the options and provide an alternative pathway for victim-survivors, which may ultimately encourage some to pursue a formal report to police.

\section{Conclusion}

In this article we have discussed the current ad-hoc uses of written reporting options in response to sexual assault, including confidential self-reporting (usually online) and initial statements taken by police in an official capacity. Ultimately, we suggest that there are distinct potential advantages to implementing an evidence-based and consistent WRIP approach to both 
confidential reporting, and initial reports of sexual assault made to police. Foremost among these is improving the consistency with which police first respond to victim-survivors as well as the evidence documented in these initial interviews. In sum, despite the evidence supporting a free narrative approach to interviewing victim-survivors of sexual assault, there is still no guarantee that the first contact that a complainant has with police will not involve a police-led interaction characterised by short-answer questions, potentially contaminating evidence and the integrity of the complainant's memories. Victim-survivors are not consistently interviewed by officers specifically trained in cognitive interviewing, and this is especially the case where a complaint emerges in the course of an investigation of another offence. A sexual assault complaint can emerge through a variety of channels, and particularly in remote or rural communities, the limited availability of specialist staff means that an initial report might well be made to a relatively junior or inexperienced officer. This can result in considerable variation in the quality of interviews with victim-survivors of sexual assault, and an inconsistent experience of justice that depends on the availability of trained staff at the moment that a victim-survivor takes the courageous step of reporting a sexual assault to police. While interviewing training continues to be updated and improved in Australian police forces, there is clearly a strong argument for seeking a sexual assault reporting approach that is more likely to result in consistency and reliability both of the evidence and of the experience of reporting for victim-survivors.

A further potential advantage lies in the use of a WRIP to gather an initial report from victimsurvivors who speak and write a language other than English (or the official language of the justice system), or who are hearing impaired. Prior research has demonstrated that interpretermediated interviews provide significantly less detail than monolingual interviews with native speakers, and that the long narrative turns so vital to cognitive interviewing are necessarily 
truncated for the purposes of interpretation. A WRIP based on the principles of cognitive interviewing, on the other hand, places minimal restrictions on the length and detail of the author's response and allows a more accurate rendering of the story into a second language through translation, or a wholly detailed report in English where a sign language interpreter would otherwise be required. Moreover, there is no requirement for the translator to be physically present and a remote translation makes no difference to the quality of the end-product, unlike telephone interpreting which, while convenient and better than using an untrained bilingual speaker as an interpreter, can greatly affect the quality of the service. While not the main focus of this paper, the evidence presented here clearly indicates that a WRIP has the potential to alleviate many of the disadvantages faced by the victim-survivor and the justice system when sexual assaults are reported in another language, including sign language.

Nonetheless there are certain challenges to be addressed before we can offer victim-survivors, the justice system and support agencies the advantages of improved anonymous reporting. While a carefully designed form-based interview such as the SAITM has been shown to improve the recall and reliability of victim-witness accounts, most form-based approaches to selfreporting are not developed in line with the research evidence regarding forensic interviewing techniques, nor have they been trialled and evaluated for their effective use in sexual assault investigations. Here we have argued that WRIP approaches do have potential to improve the consistency of reports, the experience of victim-survivors and ultimately increase the reporting rate of sexual assault. Yet, to do so, the development of such tools must reflect current best practice in forensic interviewing techniques more broadly. Improving both the rate of reporting of sexual assault, as well as the experience of victim-survivors in making initial reports, are vital 
areas for reform if we are to close the justice gap in response to sexual assault, and WRIPs may be one approach among many towards this ultimate goal.

\section{References}

ACPO. (2009). National Investigative Interviewing Strategy. Wyboston, Bedfordshire: National Policing Improvement Agency (NPIA)

Australian Bureau of Statistics. (2013). Personal safety survey. Catalogue No. 4533.0. Canberra: Australian Bureau of Statistics.

Australian Bureau of Statistics. (2006). Personal safety survey. Catalogue No. 4906.0. (Canberra: Australian Bureau of Statistics).

Baldwin, J. (1993) 'Police Interview Techniques: Establishing Truth or Proof?' The British Journal of Criminology 33(3): 325-52

Breiding, M. J., Smith, S. G., Basile, K. C., Walters, M. L., Chen, J., \& Merrick, M. T. (2014). Prevalence and characteristics of sexual violence, stalking, and intimate partner violence victimization-National Intimate Partner and Sexual Violence Survey, United States, 2011. Atlanta: Centers for Disease Control and Prevention.

Brown J (2011) We mind and we care but have things changed? Assessment of progress in reporting, investigating and prosecution of rape. Journal of Sexual Aggression, 17(3): 263-272.

Campbell, R. (2006). 'Rape survivors' experiences with the legal and medical systems: do rape victim advocates make a difference?', Violence Against Women, 12: 30-45.

Campbell, R. (2005). What really happened? A validation study of rape survivors' help-seeking experiences with the legal and medical systems. Violence and Victims, 20, 55- 68. 
Clark, H. (2015). 'A fair way to go: Justice for Victim-Survivors of Sexual Violence', in Powell, A., Henry, N. \& Flynn, A. (eds.). Rape Justice: Beyond the Criminal Law. Basingstoke: Palgrave Macmillan.

Clark, H. (2010). “What is the justice system willing to offer?': Understanding sexual assault victim/survivors' criminal justice needs', Family Matters, 85: 28-37.

Clarke, C., and Milne, R. (2001) National Evaluation of the PEACE Investigative Interviewing Course. In: Police Research Award Scheme. London: Home Office.

Daly, K. (2014). 'Reconceptualizing sexual victimization and justice'. In: Vanfraechem, I., Pemberton, A. and Mukwiza Ndahinda, F. (eds.). Justice for Victims: Perspectives on Rights, Transition and Reconciliation. London: Routledge, 378-396.

Daly, K., \& Bouhours, B. (2010). Rape and attrition in the legal process: A comparative analysis of five countries. Crime and Justice, 39(1), 565-650.

Darwinkel, E., Powell, M., \& Tidmarsh, P. (2013). Improving police officers' perceptions of sexual offending through intensive training. Criminal Justice and Behavior, 40(8), 895-908.

Elliott, I., Thomas, S., \& Ogloff, J. (2014). Procedural justice in victim-police interactions and victims' recovery from victimisation experiences. Policing and Society, 24(5), 588-601.

Elliott, I., Thomas, S. D., \& Ogloff, J. R. (2012). Procedural justice in contacts with the police: the perspective of victims of crime. Police Practice and Research, 13(5), 437-449.

Friedman, J. (2007). Reporting sexual assault of women in the military. Cardozo JL \& Gender, 14,375 .

Gabbert, F., Hope, L. \& Fisher, R. P. (2009). Protecting Eyewitness Evidence: Examining the Efficacy of a Self-Administered Interview Tool. Law \& Human Behavior, 33, 298-307. 
Geiselman, R., Fisher, R., McKinnon, P. \& Holland, H. (1985) Eyewitness memory enhancement in the police interview: cognitive retrieval hypnotics vs hypnosis. Journal of Applied Psychology, Vol. 70, No. 2, 401-412

Griffiths, A., \& Milne, R. (2006). Will it all end in tiers? Police interviews with suspects in Britain. In T. Williamson (Ed.), Investigative interviewing: Rights, research, regulation (pp. 167189). Cullompton: Willan Publishing.

Heffron, L., Busch-Armendariz, N., Vohra, S., Johnson, R. \& Camp, V. (2014). 'Giving sexual assault survivors time to decide: an exploration of the use and effects of the nonreport option', American Journal of Nursing, 114(3): 26-35.

Henry, N. (2010). The impossibility of bearing witness: wartime rape and the promise of justice. Violence against women, 16(10), 1098-1119.

Heydon, G. and Lai, M. (2013) Police Discourse in Multicultural and Multilingual Settings: An Exercise of Diminishment When Mediated by Interpreters? Investigative Interviewing: Research and Practice Vol 5(2) pp 82-98

Hohl, K., \& Stanko, E. A. (2015). Complaints of rape and the criminal justice system: Fresh evidence on the attrition problem in England and Wales. European Journal of Criminology, $12(3), 324-341$.

Hope, L., Gabbert, F., \& Fisher, R. (2011). From laboratory to the street: Capturing witness memory using the Self-Administered Interview. Legal and criminological psychology, 16, 211226.

Hope, L., Gabbert, F., Heaton-Armstrong, A., \& Wolchover, D. (2013). Self-Administered Witness Interview. Criminal Law and Justice Weekly, 177 
Johnson, H. (2012). Limits of a criminal justice response: Trends in police and court processing of sexual assault. Sexual Assault in Canada: Law, Legal Practice and Women's Activism. Ottawa: University of Ottawa Press, 640, 305-341.

Jordan, J. (2008). 'Perfect victims, perfect policing? Improving rape complainants experiences of police investigations', Public Administration, 86: 699-719.

Karjane, H.K., Fisher, B.S., \& Cullen, F.T. (2002). Campus Sexual Assault: How America's Institutions of Higher Education Respond. Final Report, NIJ Grant \# 1999-WA-VX-0008. Newton, MA: Education Development Center, Inc.

Kelly, L., Lovett, J. and Regan, L. (2005). Gap or Chasm? Attrition in Reported Rape Cases, London: Home Office.

Knowles, G. (2013). Evaluating law reform using victim/survivor stories from the criminal justice system. Sexual Abuse in Australia and New Zealand, 5(2), 40.

Lamb, M. E., Sternberg, K. J., \& Esplin, P. W. (1994) Factors influencing the reliability and validity of statements made by young victims of sexual maltreatment. Journal of Applied Developmental Psychology, Vol 15, 255-280

Lievore, D. (2003). Non-reporting and hidden recording of sexual assault: An international literature review. Canberra, Australia: Commonwealth Office of the Status of Women.

Maier, S. L. (2008). "I Have Heard Horrible Stories...” Rape Victim Advocates' Perceptions of the Revictimization of Rape Victims by the Police and Medical System. Violence against women, 14(7), 786-808.

Markham, C.J. (2015). Restricted Reporting on California Military Installations: The Unnecessary and Unwise State Law Exception. Harvard Law School National Security Journal, 
January 15, 2015 [Online]. Available at: http://harvardnsj.org/2015/01/restricted-reporting-oncalifornia-military-installations-the-unnecessary-and-unwise-state-law-exception/\# edn5

[retrieved 3 November, 2015].

Martin, P. Y. (2005). Rape work: Victims, gender, and emotions in organization and community context. New York: Routledge

McMillan, L., \& Thomas, M. (2009). Police interviews of rape victims: Tensions and contradictions. In Horvath, M. \& Brown, J. (eds.). Rape: Challenging contemporary thinking, London: Routledge, 255-280.

Milne, R., \& Bull, R. (1999). Investigative interviewing: Psychology and practice. Chichester: John Wiley \& Sons.

Ministry of Justice, Home Office, \& Office for National Statistics. (2013). An Overview of Sexual Offending in England and Wales: Statistics bulletin. London: Ministry of Justice.

Murphy, K., \& Barkworth, J. (2014). Victim willingness to report crime to police: Does procedural justice or outcome matter most?. Victims \& Offenders, 9(2), 178-204.

Police and Criminal Evidence (PACE) Act 1984 (UK). Available at: http://police.homeoffice.gov.uk/operational-policing/powers-pace-codes/pace-code-intro/ [retrieved 3 November, 2015].

Powell, A. (2015). Seeking rape justice: Formal and informal responses to sexual violence through technosocial counter-publics. Theoretical Criminology, 19 (4), 571-588.

Powell, A. and Henry, N. (in press). Policing technology-facilitated sexual violence against adult victims: police and service sector perspectives. Policing \& Society. 
Powell, M. and Cauchi, R. (2013) Victims' perceptions of a new model of sexual assault investigation adopted by Victoria Police. Police practice and research. Vol 14 (3) 228-241

Powell, M., Fisher R. and Wright, R. (2005) Investigative Interviewing In N. Brewer \& K. Williams (Eds) Psychology and Law: An Empirical Perspective. The Guildford Press: New York. pp11-42

Rich, K. (2014). Interviewing Rape Victims: Practice and Policy Issues in an International Context. Palgrave Macmillan.

Rich, K., \& Seffrin, P. (2012). Police interviews of sexual assault reporters: do attitudes matter?. Violence and victims, 27(2), 263-279.

Royal Brisbane and Women's Hospital. (2013). Fact Sheet: Alternative and Reporting Options To report or not to report. Brisbane: Queensland Government. Available at: https://www.health.qld.gov.au/sexualassault/docs/sex-reporting.pdf $\quad$ [retrieved 1 November, $2015]$.

Sauerland, M., Krix, A. C., van Kan, N., Glunz, S., \& Sak, A. (2014). Speaking is silver, writing is golden? The role of cognitive and social factors in written versus spoken witness accounts. Memory \& cognition, 42(6), 978-992.

Sexual Health Innovations. (2015). Media Release: Sexual Assault Reporting System Launches

At University of San Francisco and Pomona College. New York. Available at: https://www.sexualhealthinnovations.org/images/2015-09-

02 SHI_Press_Release_Callisto_Launch.pdf [retrieved 1 November, 2015]. 
Snook, B., Eastwood, J., Stinson, M., Tedeschini, J., \& House, J. C. (2010). Reforming investigative interviewing in Canada. Canadian Journal of Criminology and Criminal Justice, 52(2), 215-229. doi:10.3138/cjccj.52.2.215

Spohn, C., \& Tellis, K. (2014). Policing and prosecuting sexual assault: Inside the criminal justice system (p. 246). Rienner.

Spohn, C., Tellis, K., \& O’Neal, E. N. (2014). Policing and prosecuting sexual assault. Critical Issues on Violence Against Women: International Perspectives and Promising Strategies, 3, 93.

Tidmarsh, P., Powell, M. B., \& Darwinkel, E. (2012). "Whole story": A new framework for conducting investigative interviews about sexual assault. Journal of Investigative Interviewing: Research and Practice, 4, 33-44.

US Government. (2009). Sexual Assault in the Military: Hearing Before the Subcomm. on National Security and Foreign Affairs of the H. Comm. on Government Reform, 110th Cong. 44 (2008) (statement of Kay Whitley, Director, Department of Defense Sexual Assault and Response Office). Available at: http://www.gpo.gov/fdsys/pkg/CHRG110hhrg51636/html/CHRG-110hhrg51636.htm [retrieved 3 November, 2015].

Westera, N. J., \& Kebbell, M. R. (2014). Investigative Interviewing in Suspected Sex Offences. In Investigative Interviewing, pp. 1-18. New York: Springer.

WHO [World Health Organization]. (2013). Global and regional estimates of violence against women: prevalence and health effects of intimate partner violence and non-partner sexual violence. Geneva: World Health Organization. 